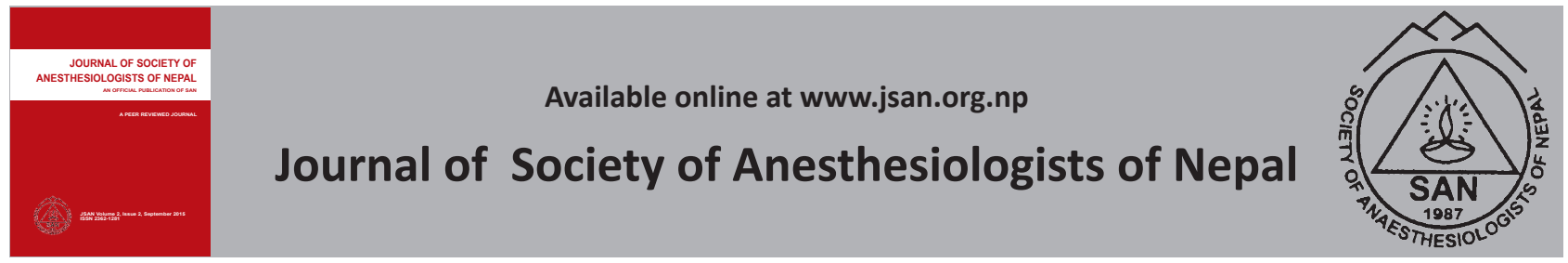

Original Article

\title{
Non opioid rectal suppositories in post cesarean delivery pain management - a randomized trial
}

Hasan Murshed ${ }^{\epsilon}$, Mozibul Haque ${ }^{\epsilon}$, Rofiqul islam ${ }^{\epsilon}$, Mahmuda Ashrafi Ferdousi ${ }^{\epsilon}$, Md Abdul Wahab $^{*}$

${ }^{€}$ Combined Military Hospital, Savar, Bangladesh.

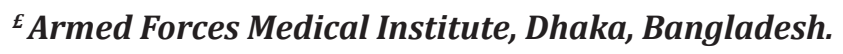

${ }^{¥}$ Armed Forces Medical College, Dhaka, Bangladesh.

\author{
ARTICLE INFO \\ Article History \\ Received 20.12.2014 \\ Accepted 07.07.2015 \\ Published 10.09.2015 \\ (C) Authors retain copyright \\ and grant the journal right \\ of first publication with the \\ work simultaneously licensed \\ under a Creative Commons \\ Attribution License that allows \\ others to share the work with \\ an acknowledgement of the \\ workss authorship and initial \\ publication in this journal.
}

\begin{abstract}
Background: Frequent administration of intravenous or intramuscular analgesics is cumbersome in developing countries where skilled nursing staffs are at scarcity. We compared analgesic efficacy between regimen using rectal suppositories only (diclofenac and paracetamol) and regimen using conventional (fixed dose schedule) intramuscular pethidine in patients undergoing cesarean section.

Methods: This prospective randomized single blind study included 144 patients undergoing both emergency and elective cesarean section. Suppositories group received diclofenac (50 mg) and paracetamol (1000 mg) suppositories regimen eight hourly for the first 24 hours. Pethidine group received intramuscular pethidine (75mg) eight hourly for the 24 hours. Effectiveness of analgesic regimen was inferred from visual pain score and satisfaction score.

Results: Mean visual pain score in two groups was not statistically significant. But higher satisfaction score (Mean \pm SD $6.36 \pm 1.306$ vs $5.83 \pm 1.061 ; p<0.05$ ) and less consumption of rescue analgesic $(p<0.001)$ was observed in suppositories group than pethidine group. No incidences of abnormal lochia /post-partum hemorrhage or other side effects were found in any study patient.

Conclusions: The analgesic regimen using suppositories has not only enhanced patient satisfaction also reduced opioid consumption, thus reduced frequency of intramuscular injection in postoperative ward following cesarean sections.

Keywords: Cesarean section; diclofenac; pain measurement; paracetamol; pethedine; rectal suppositories.
\end{abstract}

How to cite this article: Murshed $\mathrm{H}$, Haque M, Islam R, Ferdousi MA, Wahab MA. Non opioid rectal suppositories in post cesarean delivery pain management - a randomized trial. JSAN 2015;2:56-61.

Corresponding author: Col (DR) Hasan Murshed, MBBS, FCPS.

Combined Military Hospital, Savar; Bangladesh.

Telephone: +8801976877433

E-mail address: murshed673@yahoo.com 


\section{Introduction}

With the increase in number of cesarean deliveries (CD), management of post cesarean delivery pain has become a challenge for medical and nursing staff. High quality analgesia is important to promote early recovery and optimize mother's ability to care for their newborns. ${ }^{1,2}$ Most of our hospitals are using fixed dose schedule of intramuscular opioid. But use of opioids should be limited for their well documented negative effects; such as nausea, vomiting and transfer through breast milk to neonates leading transient neurobehavioral changes in neonates etc. ${ }^{3,4}$

Around the world in many institutions patient controlled analgesia (PCA) and neuraxial opioid have replaced traditional intramuscular opioid injection. In developing country with scarcity of skilled nursing stuff, along with fiscal crisis; PCA and neuraxial opioid are not convenient option. There are some serious limitations with intramuscular dosages also. Repeated intramuscular injection may be uncomfortable for many women. There is also large inter-individual variation in drug requirements and little correlation is seen between body weights with blood concentration after intramuscular injection. 5, 6

Published literatures on use of only diclofenac and paracetamol suppositories in post cesarean section pain management are limited. 7,8,9 Purpose of our study was to compare the analgesic effectiveness between regimen using rectal suppositories only (rectal diclofenac sodium and paracetamol) and regimen using conventional (fixed dose schedule) intramuscular pethidine.

\section{Materials and Methods}

A prospective randomized study was conducted over a period of 6 months from November 2013 to April 2014. Ethical approval was obtained from the institutional ethical committee. Informed consent was obtained from all patients. All elective and emergency lower segment cesarean sections under subarachnoid block (SAB) were recruited during the study period in a Military Hospital of Bangladesh.

The exclusion criteria were the presence of bronchial asthma, peptic ulcer disease on treatment, body weight $\leq 50$ and $\geq 90$, coagulopathy, severe pregnancy induced hypertension, use of analgesic within 4 hour period before operation. Patients who had an operative time of more than two hours, intraopertive injury to bowel or bladder and patients developing post dural puncture headache (PDPH) were also excluded from the present study.

The patients were allocated randomly into two groups. Group allocation was concealed in sealed opaque envelops that were not opened until informed consent had been obtained from the patients. Purposive sampling technique was applied in this research. Suppositories group (Group 1) received $50 \mathrm{mg}$ diclofenac and $1000 \mathrm{mg}$ paracetamol suppositories together, on first request for analgesic by patient's after cesarean section. Same analgesic doses were repeated eight hourly for the first 24 hours in suppositories group. Pethidine group (Group 2) received eight hourly $75 \mathrm{mg}$ intramuscular Pethidine, on first request for analgesic by patient's after cesarean section. For breakthrough pain $75 \mathrm{mg}$ intramuscular Pethidine was used as rescues analgesic in both groups.

Patients were instructed how to make use of a VAS (Visual analogue scale) graded from 0 (no pain) to 10 (most severe pain) before operation. All patients received intravenous injection of metoclopramide $10 \mathrm{mg}$ and ranitidine $50 \mathrm{mg}$ preoperatively (Half an hour before operation). Spinal anesthesia was induced in the left lateral position at L2 \& 3 or L3 \& 4 interspace using a 25-gauge Quincke spinal

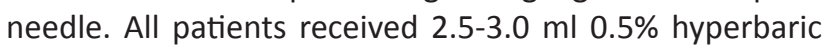
bupivacaine. The standard anesthetic and surgical techniques were followed.

Visual analog pain score was used to evaluate pain level at 2, 4, 6, 12 and 24 hours postoperatively. Observations concerning 24 hour opioid (Pethidine) consumption were documented. At 24 hour postoperatively satisfaction with post-operative pain management was evaluated on a visual analog satisfaction scale graded from 0 (unsatisfied) to 10 (excellent)

Primary outcomes on analgesic effectiveness were inferred from visual analog scale and satisfaction scale. Secondary outcome on side effect of analgesic regimen was inferred from incidence of nausea, vomiting, post partum hemorrhage, status of lochia, side effects of analgesic (such as Peptic dyspepsia, uterine atony etc.) were recorded. Nursing staff recording postoperative data were blind to group allocation.

All continuous data were presented as mean \pm Standard Deviation (SD) and categorical data presented as number (\%). Significant differences were evaluated using the unpaired Student t-test and Chi square test. A p value < 0.05 were considered as significant. All analyses were performed using SPSS 19 for Windows.

\section{Results}

A total of 144 patients were enrolled in this study with 72 patients in each group. Three women in group-1 were excluded from the study, because of PDPH (Figure 1). There were no significant differences between the two groups in term of age, weight, gravity and parity. However, gestational age was significantly $(p<0.05)$ higher in group 1. (Table 1) 
JSAN 2015; 2 (2)

Table 1: Anthropometric Measurement and Obstetric History related Data

\begin{tabular}{|c|c|c|c|}
\hline & $\begin{array}{l}\text { Group } 1 \\
\text { (Suppositories } \\
\text { group) ( } \mathrm{n}= \\
69 \text { ) } \\
\end{array}$ & $\begin{array}{l}\text { Group } 2 \\
\text { (Pethidine } \\
\text { group) (n } \\
=72 \text { ) }\end{array}$ & $\begin{array}{l}\mathbf{p} \\
\text { Value }\end{array}$ \\
\hline $\begin{array}{l}\text { Age (years) (mean } \\
\pm S D)\end{array}$ & $24.97 \pm 3.827$ & $\begin{array}{l}25.29 \\
\pm 3.69\end{array}$ & 0.613 \\
\hline $\begin{array}{l}\text { Weight (kg) (mean } \\
\pm \text { SD) }\end{array}$ & $67.96 \pm 9.539$ & $\begin{array}{l}65.13 \pm \\
10.01\end{array}$ & 0.088 \\
\hline $\begin{array}{l}\text { Height }(\mathrm{cm}) \\
\text { (mean } \pm \mathrm{SD})\end{array}$ & $150.94 \pm 3.289$ & $\begin{array}{l}151.40 \\
\pm 3.598\end{array}$ & 0.429 \\
\hline $\begin{array}{l}\text { Gravida (number) } \\
\text { (mean } \pm \text { SD) }\end{array}$ & $2.04 \pm 0.848$ & $\begin{array}{l}2.01 \pm \\
0.942\end{array}$ & 0.845 \\
\hline $\begin{array}{l}\text { Para (number) } \\
\text { (mean } \pm S D \text { ) }\end{array}$ & $0.86 \pm 0.648$ & $0.76 \pm 0.70$ & 0.425 \\
\hline $\begin{array}{l}\text { Gestational age } \\
\text { (days) (mean } \pm \\
\text { SD) }\end{array}$ & $270.58 \pm 9.881$ & $\begin{array}{l}266.14 \pm \\
11.27\end{array}$ & $0.014 *$ \\
\hline
\end{tabular}

Note: Students $\mathrm{t}$ test done between groups. ${ }^{*}=\mathrm{p}$ value significant

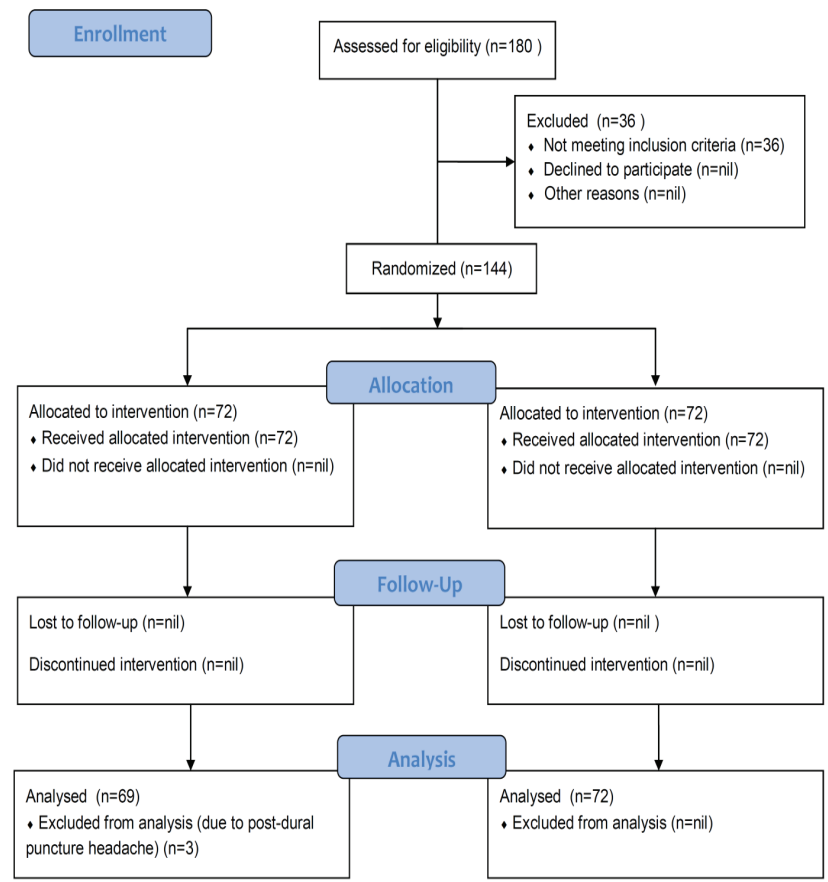

Figure 1: CONSORT 2010 Flow Diagram of the study

There was difference in the mean visual pain score in two groups in all visits but was not statistically significant except in 4 hours where pain was better controlled in the pethidine group $(p<0.05)$ (Table 2$)$. Higher satisfaction score was observed in group 1 than group 2, which was also significant $(p<0.05)$. (Table 2$)$.
Table 2: Postoperative Pain Scores and Satisfaction Scores

\begin{tabular}{llll}
\hline & $\begin{array}{l}\text { Group 1 } \\
\text { (Suppositories } \\
\text { group)(n=69) }\end{array}$ & $\begin{array}{l}\text { Group 2 } \\
\text { (Pethidine } \\
\text { group) (n }=\end{array}$ & p value \\
& & 72) & \\
\hline VAS scores at & & & \\
rest: & & & \\
(mean \pm SD) & & & \\
PACU & & $1.99 \pm 1.216$ & 0.593 \\
2 h & $2.12 \pm 1.64$ & $1.85 \pm 0.799$ & $0.042^{*}$ \\
4h & $2.19 \pm 1.154$ & $1.58 \pm 0.868$ & 0.270 \\
6h & $1.74 \pm 0.798$ & $1.89 \pm 0.897$ & 0.288 \\
12h & $1.74 \pm 0.76$ & $1.35 \pm 0.479$ & 0.099 \\
24h & $1.54 \pm 0.833$ & & \\
Satisfaction & $6.36 \pm 1.306$ & $5.83 \pm 1.061$ & $0.009 * *$ \\
scores: (mean & & & \\
\pm SD) & & & \\
\hline
\end{tabular}

Note: Students $\mathrm{t}$ test done between groups. ${ }^{*}=\mathrm{p}$ value significant, $* *=p$ value highly significant.

The Pethidine consumption was higher in group 2; which was statistically highly significant $(p<0.001)$ (Table 3 )

Table 3: Postoperative Analgesic Data

\begin{tabular}{|c|c|c|c|}
\hline & $\begin{array}{l}\text { Group } 1 \\
\text { (Suppositories } \\
\text { group) } \\
(\mathrm{n}=69)\end{array}$ & $\begin{array}{l}\text { Group } 2 \\
\text { (Pethidine } \\
\text { group) } \\
(\mathrm{n}=72)\end{array}$ & p Value \\
\hline $\begin{array}{l}\text { Pethidine } \\
\text { received in } \\
0-8 \text { hours (mg) } \\
\text { (mean } \pm S D \text { ) }\end{array}$ & $53.26 \pm 34.276$ & $75 \pm 0$ & $0.000 * * *$ \\
\hline $\begin{array}{l}\text { Pethidine } \\
\text { received in } \\
9-16 \text { hours } \\
\text { (mg) (mean } \pm \\
\text { SD) }\end{array}$ & $10.87 \pm 26.596$ & $75 \pm 0$ & $0.000 * * *$ \\
\hline $\begin{array}{l}\text { Pethidine } \\
\text { received in } \\
16-24 \text { hours } \\
(\mathrm{mg}):(\text { mean } \\
\pm S D)\end{array}$ & $\mathrm{Nil}$ & $\begin{array}{l}73.96 \pm \\
8.839\end{array}$ & $0.000 * * *$ \\
\hline
\end{tabular}

Note: Students $\mathrm{t}$ test done between groups. $* * *=\mathrm{p}$ value very highly significant

Significant $(p<0.001$ ) difference was observed between two groups regarding incidence of nausea and vomiting (Table 4). Finally no incidences of abnormal lochia/postpartum hemorrhage or other side effects were found in any study patient. 
Table 4: Side Effects in first 24 hours: Number of patients (percentage)

$\begin{array}{lll}\text { Group 1 } & \text { Group 2 } & \text { p Value } \\ \text { (Suppositories } & \text { Pethidine } & \\ \text { group) n (\%) } & \text { group n (\%) }\end{array}$

$\begin{array}{llll}\text { Nausea } & 0(0) & 9(12.5 \%) & 0.000 * * * \\ \text { Vomiting } & 0(0) & 15(20.83 \%) & \end{array}$

Note: Chi Square test done. ${ }^{* * *}=\mathrm{p}$ value highly significant

\section{Discussion}

Our study shows both postoperative pain management regimens are adequate and effective after cesarean section. Mean pain score of VAS in both group is $\leq 3 / 10$, which is not high enough to interfere with patient's functional state as shown by Dihle et al. in their study. ${ }^{10}$ Even though there is higher pain score in suppositories group at 4 hour, mean pain score of VAS is still $\leq 3 / 10$. But patient's using suppositories experienced higher level of satisfaction with reduced opioid consumption than pethidine group. Higher pain score at 4 hour in suppositories group is may be due to incomplete relive of somatic pain, as non steroidal anti inflammatory drugs (NSAIDs) are more effective in visceral pain rather than somatic pain. ${ }^{11.12,13}$

NSAIDs have been effective for relieving pain related to menstrual cramping and as a result there has been interest in the use of NSAIDs to treat visceral component of pain after caesarean delivery. Diclofenac, being an NSAID is act via inhibiting prostaglandin synthesis; hence its efficacy in post-caesarean analgesia by the reduction of pain from uterine contractions and also due to central anti-nociceptive effect has been postulated. ${ }^{14,15}$ Diclofenac has advantages in lactating mother for being low concentration in breast milk. ${ }^{12}$ In suppositories form absoprption of diclofenac from rectal mucosa is rapid and giving peak plasma concentration after about $1 \mathrm{~h}$ but oraly it takes 2-3 $\mathrm{h}$ and substantial amount is also removed by hepatic first pass metabolism. Parcetamol absorption through rectum is variable and time required to reach peak blood concentration is little longer than 3060 minutes. Unfortunately, NSAIDs alone are insufficient to treat post-caesarean delivery pain effectively. ${ }^{16}$ Thus paracetamol also added to our multimodal analgesic regimen due its additive effect with diclofenac on opioid spare and reduction of opioid related side effects as shown by Maund E et al. ${ }^{17}$ Therapeutic effect of diclofenac is 3-4 times longer than its half life in plasma, because pain mediating prostaglandins remains inhibited despite decrease of diclofenac concentration in plasma. ${ }^{13}$ In our suppositories group (Group 1) 12 (17.4\%) patient did not received any rescue dose of Pethidine in 24 hour observation period, each of remaining 57 patients have received only single rescue dose of $75 \mathrm{mg}$ intramuscular pethidine. Opioid sparing effect of paracetamol and diclofenac combination is consistent with the study of Maund et al. and Dhal et al. ${ }^{17,18}$ In pethidine group (Group 2) all 72 patients have received three dose of 75 mg intramuscular opioid at 8 hourly interval over 24 hour without any rescue dose of opioid however, satisfaction scores are lower in the suppositories group (Mean $\pm S D$ : $5.83 \pm 1.061$ vs $6.36 \pm 1.306$; $p$ value: 0.009 ). Analgesic effect of pethidine is dependent on continuous stimulation of opiate receptors and when given intramuscularly repeated dose at 3-4 hourly is necessary. ${ }^{13}$ Thus pethidine in fixed dose schedule does not provide persistant relive of pain, moreover pharmacodynamic variability with intramuscular injection may have cause lower satisfaction score in pethidine group.

Pain after cesarean section has two components: one is visceral (due to uterine contraction) and other is somatic (from the abdominal wall incision). Such complex pain is often better treated by multimodal analgesic. Diclofenac act on visceral component of pain and opioid act on somatic component better. Thus using opioid as rescue analgesic in suppositories regimen resulting in significantly more efficacious relief of pain after cesarean delivery, which is also consistent with different studies. ${ }^{11.12,13}$

Mean VAS $\leq 3 / 10$ in different time period in our study is not consistent with similar study by Haleh et al and Jakkrid et al where VAS is higher (7.09 \pm 1.06 ; $62.05 \pm$ 30.00). ${ }^{7,8}$ Haleh et al and Jakkrid et al in their studies used only diclofenac. In our study we added paracetamol with diclofenac which is the possible cause of low VAS score in our study. The addition of paracetamol and non-steroidal anti-inflamatory drugs (NSAIDs) in a multimodal approach to pain relief after cesarean delivery in our study has been very successful to potentiate the opioid effects, decrease its consumption and side effects like other similar studies. 19,20 This finding is also supported by meta-analysis of Hyllested et al. ${ }^{9}$

In term of side effects such as nausea and vomiting, it is lower in suppositories group. This low incidence of nausea and vomiting is also consistent with opioid sparing effect. Study also found no significant difference in 24 hour lochia discharge. No patient has raised objection on route of drug administration and neither complain of peptic dyspepsia.

In postpartum period diclofenac has an advantage in lactating mother for being found to be used safe without tocolysis. ${ }^{21,22,23}$ Pethidine as well as its metabolites (norpethidine) are secreted in colostrums and breast milk. ${ }^{21}$ Neonatal elimination half-lives for pethidine ( $t_{1 / 2}=13$ $\mathrm{hr}$ ) and nor-pethidine (t $1 / 2=63 \mathrm{hr}$ ) are usually prolonged. So mother receiving multiple doses of pethidine lead to not only progressive increase in neonatal plasma opioid concentration but also increase risk of nor-pethidine toxicity; resulting neonatal neurobehavioral depression. ${ }^{3}$ Kluhnert et al. documented accumulation of nor-pethidine in maternal plasma after multiple pethidine doses. ${ }^{23}$

Uses of frequent intravenous or intramuscular analgesics 


\section{JSAN 2015; 2 (2)}

are cumbersome in our country where skilled nursing staffs are at scarcity. Diclofenac and paracetamol suppositories are available in most of our general hospitals and its administration requires no supervision of skilled nursing staff or instrumentation. Moreover uses of diclofenac and paracetamol suppositories are less costly than injection pethidine. In our part of the world intrathecal fentanyl is widely used, but the effects are too short lived to be adequate for postoperative pain relief and they do not alter 24 hour opioid consumption. ${ }^{24}$

We observed a few limitations in our study. Pain perception varies among different individuals for the same procedure. The education and socioeconomic status may also have its influence on the pain perception. This data is lacking in our study. Moreover NSAIDs drug itself has some limitation in its use in patient with bronchial asthma, known peptic dyspepsia, kidney disease and low platelet count, although not absolute contraindication.

Considering above limitation, in developing country, where scarce skilled nursing staffs are overworked with routine patient's medication, our analgesic regimen using suppositories may be of value in post cesarean delivery pain. Although our analgesic regimen using suppositories is based on non-opioid drug but opioid requirement is still persist. Availability of intravenous formulation of acetaminophen will reduce the amount of suppositories, which is available in many parts of the world. Better understanding of the pathophysiology of pain is allowing us to introduce a more balanced multimodal approach to postoperative analgesia. ${ }^{1,2,25}$

In order to meet the international standard of pain management, an ideal post cesarean analgesic regimen require proper utilization of resources to formulate a methods which is cost effective, simple to implement, and has minimal impact on staff workload. We have shown that the use of suppositories may form an important part of multimodal analgesic regimen in post operative cesarean section pain management in developing world. However further study on this regimen in different center needed to justify its use in routine practice.

\section{Conclusion}

Our analgesic regimen using rectal suppositories for the management of post recession pain may be a suitable alternative to traditional and highly practiced fixed dose intramuscular pethidine Anesthesiologist and obstetrician should walk together to develop and formulate an international standard and ideal post cesarean analgesic regimen which is cost effective, simple to implement and has and has minimal impact on standard practice.

Acknowledgments: Author acknowledged the significant contribution of $\mathrm{Dr}$ (Col) Mohammad Mominur Rahman Mamun MPH, Mphil in reviewing statistical analysis of article.

\section{Conflict of Interest Statement: Ni}

\section{References}

1. Pan PH. Post cesarean delivery pain management: Multimodal approach. Int J Obstet Anesth 2006;15:185-8.

2. Leung A. Postoperative pain management in obstetric - New challenges and solutions. J Clin Anesth 2004;16:57-65.

3. White PF. The role of non-opioid analgesic techniques in the management of pain after ambulatory surgery. Anesth Analg 2002;94:577-85.

4. Wittels B, Scott DT, Sinatra RS. Exogenous opioids in human breast milk and acute neonatal neurobehavior: a preliminary study. Anesthesiology 1990;73:864-9.

5. Austin KL, Stapleton JV, Mather LE. Multiple intramuscular injections: a major source of variability in analgesic response to meperidine. Pain 1980;8:47-62.

6. Austin KL, Stapleton JV, Mather LE. Relationship between blood meperidine concentration and analgesic response. Anesthesiology 1980;53:460-6

7. Haleh R, Seyed NH, Seyed NM, Parvin T, Fatemeh K. Comparison of diclofenac with Pethidine on the pain after casarean section. International Journal of Pharmacology 2007;3:201-3.

8. Jakkrid S, Yuen T. Intramuscular diclofenac for analgesia after cesarean delivery: A randomized controlled trial. J Med Assoc Thai 2009;92:733-8

9. Hyllested M, Jones S, Pedersen JL, Kehlet H. Comparative effect of paracetamol, NSAIDs or their combination in postoperative pain management: a qualitative review. Br J Anaesth 2002; 88:199-214.

10. Dihle A, Crna M; Helseth S, Paul S, Miaskowski C. The exploration of the establishment of cut points to categorize the severity of acute postoperative pain. Clin J Pain 2006;22:617-24.

11. Olofsson $\mathrm{Cl}$, Legeby $\mathrm{MH}$, Nygards EB, Ostman KM. Diclofenac in the treatment of pain after cesarean delivery. An opiod saving strategy. Eur J Obstet Gynecol Reprod Biol 2000;88:143-6.

12. Lim NL, Lo WH, Chog A. Single dose diclofenac suppositories reduces post caesarean PCEA requirement. Can J Anesth 2001;48:383-6.

13. Rashid M, Jaruidi HM. The use of rectal diclofenac for post cesarean analgesia. Saudi Med J 2000;21:145-9.

14. Juran I, Brune K. Central effect of non-steroid antinflamatory agent: indomethacin, ibuprofen and diclofenac determined in C fibre-evoked activity in single neuron of the rat thalamus. Pain 1990;41:71-80.

15. Ferreira SH, Lorenzetti BB, Correa FMA. Central and peripheral antialgesic action of aspirin-like drugs. Eur J Pharmacol 1978;53:3948.

16. Lowder JL, Shackelford D, Holbert D, Beste TM. A randomized controlled trial to compare ketorolac tromethamine versus placebo after cesarean section to reduce pain and narcotic usage. Am J Obstet Gynecol 2003;189:1559-62. 
17. Maund E, McDaid C, Rice S, Wright K, Jenkins B, Woolacott N. Paracetamol and selective and non-selective non-steroidal antiinflammatory drugs for the reduction in morphine-related sideeffects after major surgery: a systematic review. British Journal of Anaesthesia 2011;106:292-7.

18. DahI V, Hagen IE, Sveen AM, Norseng H, Koss KS, Steen T. High-dose diclofenac for postoperative analgesia after elective caesarean section in regional anaesthesia. International Journal of Obstetric Anesthesia 2002;11:91-4

19. Bush D, Lyons G, Macdonald R. Diclofenac for analgesic after caesarean section. Anaesthesia 1992;47:1075-7.

20. Hodsman NB, Burns J, Blyth A, Kenny GN, McArdle CS, Rotman $H$. The morphine sparing effects of diclofenac sodium following abdominal surgery. Anaesthesia 1987;42:1005-8.

21. Findlay JWA, Deangelis RL, Kearney MF, Welch RM, Findlay JM. Analgesic drugs in breast milk and plasma. Clin Pharmacol Ther 1981;29:625-33.

22. Spigset 0 . Anaesthetic agents and excretion in breast milk. Acta Anaesthesiol Scand 1994;38:94-103.

23. Ostensen M, Husby G. Antirheumatic drug treatment during pregnancy and lactation. Scand J Rheumatol 1985;14:1-7.

24. Kluhnert BR, Philipson EH, Kuhnert PM, Syracuse CD. Deposition of meperidine and normeperidine following multiple doses during labour. Am J Obstet Gynecol 1985;151:406-9.

25. Ismail S, Shahzad K, Shafiq F. Observational study to assess the effectiveness of postoperative pain management of patients undergoing elective cesarean section. J Anaesthe Clin Pharmacol 2012;28:36-40.

26. Beaulieu P. Non-opioid strategies for acute pain management. Can J Anaesth 2007;54:481-5. 